\title{
In search of the mechanism that shapes the neutrophil's nucleus
}

\author{
Katia Georgopoulos \\ Cutaneous Biology Research Center, Massachusetts General Hospital, Harvard Medical School, Charlestown, \\ Massachusetts 02129, USA
}

\begin{abstract}
The organization of the genome within the confines of the nuclear compartment is considered a key contributor to transcription and DNA replication, repair, and recombination. A typical higher eukaryotic cell has a spherical nucleus that is $\sim 10 \mu \mathrm{m}$ in diameter. This is not the case for a neutrophil, a short-lived innate immune cell with an unusual multilobular nuclear structure that may serve purposes outside nuclear functions. In this issue of Genes \& Development, Zhu and colleagues (pp. 141-153) investigate the neutrophil's genome organization and the mechanisms that contribute to its unique nuclear shape.
\end{abstract}

The multilobular shape of a neutrophil's nucleus is thought to contribute to its fluidity and ability to crawl through the endothelial lining of blood vessels and interstitial spaces. These cellular properties are critical for rapid participation in the first line of an immune response (Kolaczkowska and Kubes 2013). Mutations in the Lamin $B$ receptor (LBR), a nuclear envelope protein, result in the loss of the neutrophil nucleus's distinctive shape and impair cell migration, suggesting that the mechanisms controlling the shape of a neutrophil's nucleus are critical for its function (Gaines et al. 2008).

In the present study, Zhu et al. (2017) first investigated how the genome is organized in the nucleus of a neutrophil. By combining both genome-wide Hi-C (chromosome capture followed by high-throughput sequencing) and FISH for a candidate locus-specific approach, the investigators could interrogate the changes in chromosomal interactions that take place as a mononuclear myeloid progenitor differentiates into a polymorphonuclear neutrophil. Using these powerful methodologies, they found that short-range intrachromosomal interactions $(<3 \mathrm{Mb})$ prevalent in myeloid progenitors are depleted in neutrophils, whereas long-range $(>3 \mathrm{Mb})$ intrachromosomal and interchromosomal interactions are greatly enriched.

It has been reported previously that, in cells with a globular nucleus, such as in the myeloid progenitors used by

[Keywords: genome topology; Lamin B receptor; neutrophils; nucleoli; rDNA]

Corresponding author: katia.georgopoulos@cbrc2.mgh.harvard.edu Article is online at http://www.genesdev.org/cgi/doi/10.1101/gad.296228. 117.
Zhu et al. (2017), long-range chromosome interactions fall into two classes (Fig. 1, class A and class B) and that interactions between the two classes are mutually exclusive (Lieberman-Aiden et al. 2009; Kalhor et al. 2011; Rao et al. 2014). Class A is enriched for active chromosomal regions defined by the presence and expression of genes, DNase I hypersensitivity, and open or bivalent chromatin, whereas class B displays an opposite pattern that is enriched for restrictive chromatin. Notably, the majority of chromosomal domains that switch from short-range to long-range interactions either belongs to class $\mathrm{B}$ in both myeloid progenitors and neutrophils or switches to class B upon differentiation. This indicates that although long-range chromosome interactions are not exclusive to repressed chromatin, any de novo interactions manifested in the neutrophil's nucleus are mostly between repressed chromatin domains. Notably, genes associated with domains that switch to long-range interactions in a neutrophil are already in a transcriptionally repressed chromatin environment marked with deposition of the Polycomb complex repression mark H3K27me3 in myeloid progenitors. Consequently, the increase in the neutrophil's long-range chromosomal interactions does not correlate with changes in gene expression that occur upon differentiation into a neutrophil. Thus, this increase in long-range interactions between repressed chromosomal domains may serve or reflect a structural process that is distinctive to the neutrophil.

The investigators next simulated the neutrophil's chromosomal contact data ( $\mathrm{Hi}-\mathrm{C})$ in the confines of a spherical or toroidal nuclear shape to generate three-dimensional genome population models (Kalhor et al. 2011). Using this approach, they show that chromosomes in the neutrophil's toroidal nucleus have a substantially smaller radius of gyration compared with the spherical nucleus of the myeloid progenitor, indicating chromosome compaction in space. After modeling the myeloid progenitor's chromosomal contact data in the confines of a toroidal nucleus, the investigators found similar results and

(C) 2017 Georgopoulos This article is distributed exclusively by Cold Spring Harbor Laboratory Press for the first six months after the full-issue publication date (see http://genesdev.cshlp.org/site/misc/terms.xhtml). After six months, it is available under a Creative Commons License (Attribution-NonCommercial 4.0 International), as described at http:// creativecommons.org/licenses/by-nc/4.0/. 

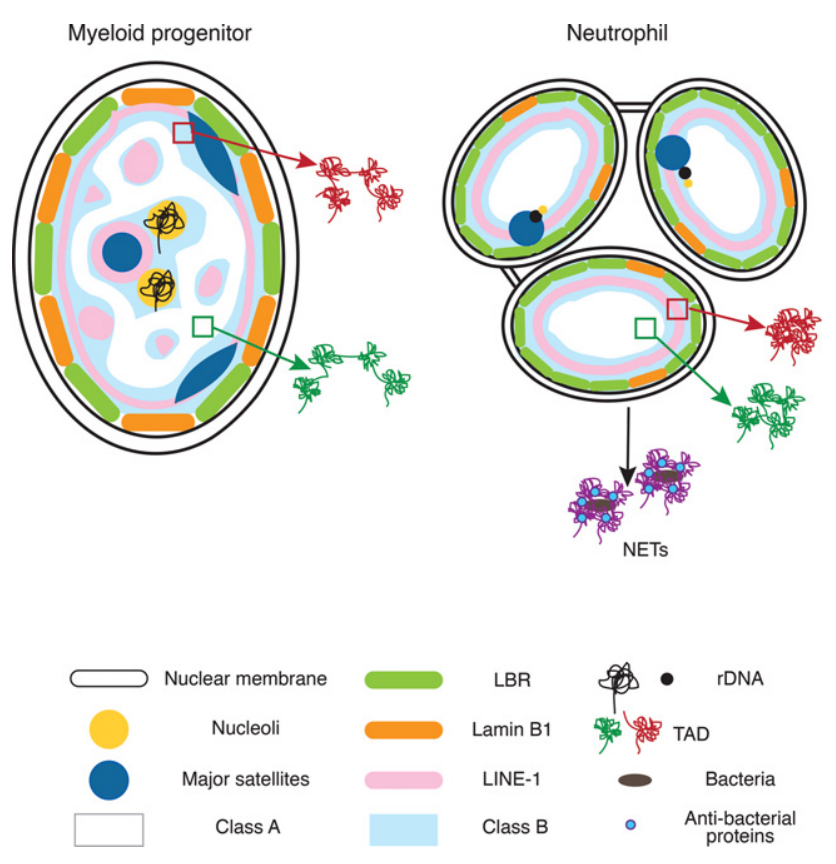

Figure 1. Hallmarks of the unique nuclear morphology of a neutrophil. Two subnuclear areas (class A and class B) with mutually exclusive chromosome interactions are depicted for a myeloid progenitor (left) and a differentiated neutrophil (right). The class A area is associated with chromosome regions that are generich and transcriptionally active with open chromatin, whereas class B is rich in DNA repeats and associated with repressed chromatin. Topologically associated chromosome domains (TADs) residing within class A or B areas are color-coded as green or red. Differentiation into a neutrophil is accompanied by displacement of repressed chromosomal regions (class B) that contain centromeres (major satellites), long interspersed nuclear element 1 (LINE-1), and ribosomal DNA (rDNA) repeat elements from the nuclear interior into the nuclear periphery with supercontraction. A change in the abundance of structural proteins such as Lamin B is indicated. The release of neutrophil extracellular traps (NETs) that contain chromatin and antibacterial proteins as part of a process that eliminates invading micro-organisms is also shown.

concluded that the toroidal nuclear shape is the driver of chromosome compaction.

What determines the toroidal shape? To answer this question, the investigators evaluated the neutrophil's genome-organizing elements (Fig. 1). DNA repeat elements involved in the organization of subnuclear compartments that belong to class $\mathrm{B}$ were tested. They show that ribosomal DNA (rDNA) repeat elements that serve as nucleolus-organizing centers and are normally present in the nuclear interior of a myeloid progenitor were relocated at the nuclear lamina of a neutrophil, where they become contracted (Pederson 2010). This nucleolus relocation to the nuclear lamina correlated with a shut down in ribosomal RNA (rRNA) synthesis that is tolerated by the short-lived neutrophil. Displacement and spatial contraction of centromeric repeats to the nuclear periphery in neutrophils compared with myeloid progenitors was also observed. Notably, these were the only interchromosomal contacts that were specific to the neutrophil. Finally, long interspersed nuclear repeat elements (LINEs), the most abundant class of active autonomous transposons that are repressed by the Polycomb complex (Ishak et al. 2016), were also displaced to the nuclear lamina of the neutrophil. Thus, heterochromatin-associated DNA repeats are specifically displaced to the nuclear periphery of the neutrophil, suggesting that relocation of class B chromosomal regions from the nuclear interior may be critical for its nuclear shape (Fig. 1).

Next, the investigators addressed the role of chromatinassociated factors in dictating nuclear shape, with LBR at the top of the list. They show that while displacement of centromeres to the nuclear lamina was dependent on LBR, displacement of LINE repeat elements was not. As LBRmediated location of centromeres to the nuclear periphery has been reported in a variety of cells, such as lymphocytes, that do not have a toroidal nucleus, this is unlikely to be the mechanism by which this structural factor contributes to a multilobular nuclear shape. The role of nuclear factors that regulate chromosome loop formation, such as CTCF (loop anchor) and the RAD21 component of the cohesin complex (loop extruder), was also tested. Although no difference in CTCF enrichment was seen at the domains that switch to long-range interactions in neutrophils, a depletion of RAD21 was detected. One possible explanation for the lack of RAD21/cohesin from these sites could be replacement with another loop extrusion complex, such as condensins. Another possibility is the removal of these loop extrusion complexes, since the process of chromosome compaction has already been performed in a neutrophil.

In summary, Zhu et al. (2017) provide first insights into how the genome is organized within the toroidal-shaped nucleus of a neutrophil and open up new areas of research into this intriguing subject. They show that restriction of chromosomes in the smaller area of a neutrophil's nucleus requires a powerful chromosome compaction process. The specific increase in long-range interaction between repressed chromosome regions is not an obvious prediction, suggesting that repressed chromatin and its contributing factors may play a key role in nuclear reorganization. Future studies should further evaluate how structural proteins such as LBR and regulators of chromosome condensation such as cohesins and condensins contribute to the change in nuclear morphology. Are LINEs used in combination with chromatin-organizing factors to pull the neutrophil's nucleus into shape? Since most of the chromosomal regions displaced to the neutrophil's nuclear lamina and engaged in de novo long-range chromosome interactions are regulated by Polycomb, is this repression complex required for shaping the nucleus of the neutrophil?

Finally, the genomic organization of the neutrophil might seem curious in the context of the limited requirement for new protein synthesis in these short-lived cells. In this context, a distinctive function for the chromatin in dying neutrophils is intriguing. The expiring neutrophil releases its chromatin as a net that includes antibacterial proteins (Kolaczkowska and Kubes 2013). This neutrophil extracellular trap (NET) helps to eliminate invading 
microorganisms (Fig. 1). Might the distinctive long-range interactions of neutriphils' heterochromatin be the precursor in the construction of this NET-like structure? In conclusion, this study opens up new areas of investigation into not only how the nucleus is shaped but also for what purpose.

\section{Acknowledgments}

I thank Dr. T. Yoshida for the artwork on the model presented by Zhu et al (2017). K.G. is supported by 5R01CA162092, 4R01 CA158006, 5R01CA190964, 1R21 AI124326, 1R01 AR069132, and a J. de Gunzburg Massachusetts General Hospital Scholar Award.

\section{References}

Gaines P, Tien CW, Olins AL, Olins DE, Shultz LD, Carney L, Berliner N. 2008. Mouse neutrophils lacking lamin B-receptor expression exhibit aberrant development and lack critical functional responses. Exp Hematol 36: 965-976.

Ishak CA, Marshall AE, Passos DT, White CR, Kim SJ, Cecchini MJ, Ferwati S, MacDonald WA, Howlett CJ, Welch ID, et al.
2016. An RB-EZH2 complex mediates silencing of repetitive DNA sequences. Mol Cell 64: 1074-1087.

Kalhor R, Tjong H, Jayathilaka N, Alber F, Chen L. 2011. Genome architectures revealed by tethered chromosome conformation capture and population-based modeling. Nat Biotechnol 30: 90-98.

Kolaczkowska E, Kubes P. 2013. Neutrophil recruitment and function in health and inflammation. Nat Rev Immunol 13: 159-175.

Lieberman-Aiden E, van Berkum NL, Williams L, Imakaev M, Ragoczy T, Telling A, Amit I, Lajoie BR, Sabo PJ, Dorschner $\mathrm{MO}$, et al. 2009. Comprehensive mapping of long-range interactions reveals folding principles of the human genome. Science 326: 289-293.

Pederson T. 2010. 'Compact' nuclear domains: reconsidering the nucleolus. Nucleus 1: 444-445.

Rao SS, Huntley MH, Durand NC, Stamenova EK, Bochkov ID, Robinson JT, Sanborn AL, Machol I, Omer AD, Lander ES, et al. 2014. A 3D map of the human genome at kilobase resolution reveals principles of chromatin looping. Cell 159: 1665-1680.

Zhu Y, Gong K, Denholtz M, Chandra V, Kamps MP, Alber F, Murre C. 2017. Comprehensive characterization of neutrophil genome topology. Genes Dev (this issue). doi: 10.1101/ gad.293910.116. 


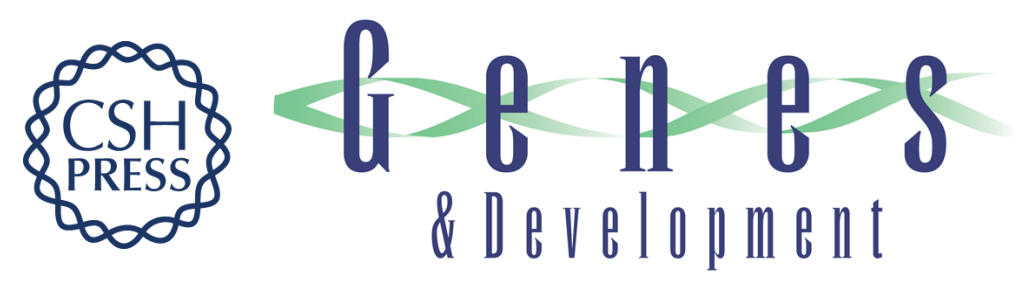

\section{In search of the mechanism that shapes the neutrophil's nucleus}

Katia Georgopoulos

Genes Dev. 2017, 31:

Access the most recent version at doi:10.1101/gad.296228.117

Related Content Comprehensive characterization of neutrophil genome topology

Yina Zhu, Ke Gong, Matthew Denholtz, et al.

Genes Dev. January , 2017 31: 141-153

References This article cites 8 articles, 2 of which can be accessed free at:

http://genesdev.cshlp.org/content/31/2/85.full.html\#ref-list-1

Articles cited in:

http://genesdev.cshlp.org/content/31/2/85.full.html\#related-urls

Creative This article is distributed exclusively by Cold Spring Harbor Laboratory Press for the first

Commons

License

six months after the full-issue publication date (see

http://genesdev.cshlp.org/site/misc/terms.xhtml). After six months, it is available under a Creative Commons License (Attribution-NonCommercial 4.0 International), as described at http://creativecommons.org/licenses/by-nc/4.0/.

Email Alerting Receive free email alerts when new articles cite this article - sign up in the box at the top Service right corner of the article or click here.

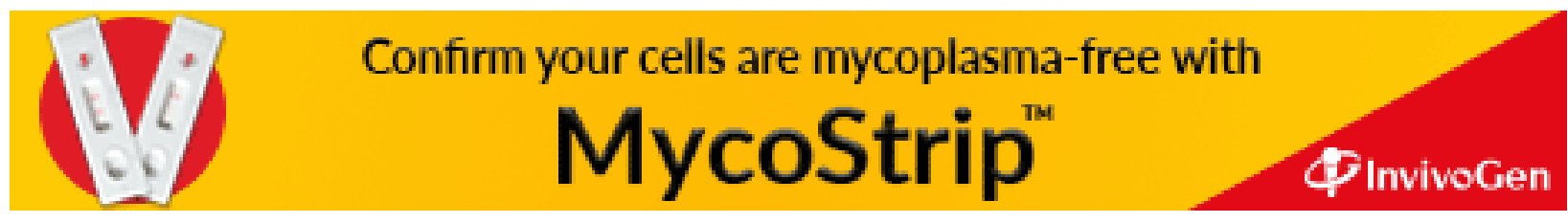

